\title{
Impact of Mental Disorders in Terms of Discrimination and Stigmatization: A Cross-Sectional Study in Peshawar, Khyber Pakhtunkhwa.
}

\author{
Farzana Daniel, ${ }^{1}$ Nasreen Ghani, ${ }^{1}$ Sardar Ali, $^{2}$ Muhammad Suliman. ${ }^{3}$
}

\begin{abstract}
Background: Developing countries are facing maternal and infant mortalities, in which maternal infections and preventable conditions during pregnancy are cardinal factors. In low-income countries, mortality related to hospital infections accounts for $36 \%$ of total newborn mortality. Despite, patient care and global progress in reducing maternal mortality, sepsis is still a major cause of preventable maternal mortality. Pakistan's health care system is not adequately prepared, especially for workers to transit from an emergency haphazard care to organize proper standardized care.

Objectives: To determine the impact of mental disorders in terms of discrimination and stigmatization.

Materials and Method: A cross-sectional study was conducted in psychiatry units of three tertiary care hospitals of Peshawar, Khyber Pakhtunkhwa. Data was collected from 432 participants through a structured questionnaire using a convenient sampling technique. The duration of the study was six months. Data were analyzed using SPSS V.23.

Results: The mean ages of the participants are $34 \pm 4.45 .6 \%$ of participants were married, while $54.19 \%$ were unemployed. $19.9 \%$ quit their job due to disease. $52 \%$ reported mental health adversely affected their relationships with family members. Moreover, $65.05 \%$ of people reported that their overall socializing skills have been negatively affected by the mental illnessrelated stigma. $72.9 \%$ of the participants reported that they are stigmatized due to their mental health disorders.

Conclusion: It is noted that a large number of people are being stigmatized due to their mental illness. This stigma is affecting their lives, especially their family dynamics, educational attainments and behavior of peers at their workplace. The disease process disturbed the education, employment and social status of mentally disordered patients.
\end{abstract}

Keywords: Depression, Mental Disorders, Stigmatization, Discrimination.

This article may be cited as: Daniel F, Ghani N, Ali S, Suliman M. Impact of Mental Disorders in Terms of Discrimination and Stigmatization: A Cross-Sectional Study in Peshawar, Khyber Pakhtunkhwa. J Saidu Med Coll Swat. 2021;11(2):96-102

\section{INTRODUCTION}

Mental disorders are a major problem of concern nowadays. Around 450 million people are currently suffered from mental health problems. Mental health problems affect one in four people. ${ }^{1}$ Anxiety and depression are the main two leading disorders that contribute mainly to mental health problems. $^{2}$ The essence of mental disorders as rising global concern is being reflected by the fact that health-related goals for Sustainable Development Goals (SDGs) have included specific targets for the issue. ${ }^{3}$ Approximately, every year 8 million people died due to mental health disorders worldwide. ${ }^{4}$ The mortality rate varies due to the co-morbidities of mental health disorders, the majority of the patients do not die due to their conditions but died due to the associated condition such as heart diseases, suicides and severe infections. ${ }^{5}$ Certain healthrelated problems such as severe infections, cardiac problems, suicides, injuries, and accidents are linked with mental health disorders. ${ }^{6}$

\section{Public Health School Nishterabad Peshawar \\ 2.Institute of Nursing Sciences Khyber Medical University \\ Peshawar \\ 3.Upper Swat College of Nursing Frahatabad Swat}

Correspondence: Nasreen Ghani

Assistant Professor (MSN)

Institute of Nursing Sciences Khyber Medical University Pashawar.

Email: nasreenghani.ins@kmu.edu.pk

nasreen_shaheen@hotmail.com

Received: June 10, 2020 Accepted: March 26, 2020
Mental disorder is a heterogeneous group of diseases that range from anxiety, depression to schizophrenia, acute psychosis, and epilepsy. Being a very broad disease group, the modes and options for interventions are also quite broad and encompassing. ${ }^{7}$ People live in an environment with multiple physical and psychological stimuli. These stimuli form the experiences of human beings and as per their learned experience, people respond differently to different kinds of stimuli in different situations. On the other hand, negative stimuli bring stress to the coping mechanisms and this stress. ${ }^{8}$

Various stressors come into play as part of the normal life cycles at different stages of life. Preparing for exams or marriage ceremonies are expected stressors and their impact usually is mild to moderate. Unexpected and harsher stressors like the death of a family member, however, can have significant impacts, including inflicted a mental disorder like schizophrenia. ${ }^{9}$ The role of the social constructs in causation and prolongation of mental disorders is well established. Studies have shown that social supports rendered by family members towards schizophrenia patients have a lessening effect on the symptoms of disease severity. ${ }^{10}$ Hence the social construct is established in disease causation, it also arguably has a role in its remedy and controlling its adverse outcomes. When social exclusion is the trigger, reintegration is the remedy for mental disorders. 
Also, in established cases of mental disorders, workplace interventions, family support, and positive societal attitude have shown better outcomes for the patients. Evidence shows that "wrongly labeling" a fit person with "mental disorder" can lead to the causation of "mental disorder". Similarly, the negative behavior of the society, discrimination at home or stigmatization in the work environment can lead to complications of mental illnesses. ${ }^{11}$

Conformal with the rising global trend, mental health conditions are also becoming more and more prevalent in developing countries like Pakistan. Reportedly, $15 \%$ of men in the general population and around $46 \%$ of women suffer from one or another kind of mental illness. Among these mental disorders, around $6 \%$ of people have clinical depression, 1-2\% people are having epilepsy, and $1.5 \%$ is living with schizophrenia while around $1 \%$ of people have Alzheimer's. ${ }^{12}$ With the huge burden of mental diseases in Pakistan, special interventions are needed in Pakistan to minimize the ratio of mental health problems. Unfortunately, apart from the high prevalence of the disease in society, various cultural and societal tendencies further deteriorate the living condition and quality of life of all those living with mental disorders in the country. ${ }^{13}$ The current study is therefore, designed to identify the impact of mental health disorders in terms of discrimination and stigmatization.

\section{MATERIALS AND METHODS}

A Cross-sectional study was conducted in three tertiary hospitals of Peshawar, Khyber Pakhtunkhwa. Participants were recruited from Psychiatric outpatient departments of Lady Reading hospital, Mental Hospital and Shafiq Psychiatric clinic Peshawar. The study was carried out in six months (October 2017 to March 2018).

Overall, 432 participants were included in the study using a Non-probability sampling technique (convenient sampling technique). 144 participants were selected from each hospital. Patients diagnosed with anxiety, depression, and schizophrenia was included in the study, and those having an acute attack of psychosis and history of less than 6 months were excluded.

The sample size was calculated using the WHO sample size calculation formula. With a $95 \%$ confidence level, the margin of error of $5 \%$ and with anticipated population proportion of $49 \%$ the required sample size estimated is 385 . Estimating a non-response rate of $10 \%$, the sample calculated as 432 subjects.

The study was conducted after approval from KMU ethical board and research committee. A structured questionnaire was used to collect the data. The questionnaire was validated from experts before going to the field and was test piloted with a $10 \%$ sample size. The test reliability (Cronbach's alpha) of the questionnaire is 0.871 . Informed consent was granted from the participants before the collection of data. Data were analyzed using SPSS V.23.

\section{RESULTS}

A total of 432 participants were included in the study. The mean age of the study participants was 34.37 years and their average income per month was Rs.31826/-. Their ages ranged between 12 and 82 years while income levels ranged from Rs.5000 to Rs. 83000. Average time since diagnosis was 3.47 years, although there was great variation in individual cases. The minimum interval between diagnosis and time of this study was one year while the maximum interval was 20 years.

Majority (35.63\%) of the participants were illiterate followed by matriculates $(n=84,19.44 \%)$. Another $18.52 \%(80)$ had primary education followed by $17.82 \%(n=77)$ with graduation and $8.5 \%(n=37)$ had masters level qualification. Less than half $(n=197,45.60 \%)$ participants were unmarried while $38.19 \% \quad(n=165)$ were married. Another $6.71 \%(n=29)$ were divorced while $7.18 \%(n=31)$ were widowed. People who were married but living separately were $2.31 \%(n=10)$. More than half $(54.19 \% \quad(n=233)$ of the respondents were unemployed while $45.81 \% \quad(n=197)$ were employed. The majority of the respondents $(69.91 \%)$ were living in a joint/extended family while less than half (30\%) lived in a nuclear family.

The vast majority of the respondents relied on their parents for care $(n=172,39.81 \%)$ followed by the spouse $(n=112,25.93 \%)$. In $19.91 \%$ of cases $(n=86)$ children provide care to their parents. Another $13.43 \% \quad(n=58)$ relied on support from distant relatives while only $0.93 \% \quad(n=4)$ had access to professional nursing care at home. These counts signify the reliance on informal care of those suffering from mental health conditions. 
Similarly, participants reporting to have diminished performance at work after being diagnosed with a mental disorder were more in numbers $(28.94 \%, n=125) .26 .85 \%$ of study respondents reported that they have been discriminated against under their diagnosis of mental health illness. Around a quarter of the respondents $(19.91 \%, \mathrm{n}=86)$ reported having considered quitting their job after being diagnosed with mental illness (Table 1).

The majority of respondents $(54.63 \%, n=236)$ reported they feel uneasy when people ask them about their illness. Hence, a majority of people reported being uneasy with discussing their mental illnesses. The vast majority of the population reported that their socialization skills have worsened after being diagnosed with mental illness. Those who were reported worsening of socialization skills were $61.81 \% \quad(n=267)$. Similarly, another majority with $64.12 \%(n=277)$ reported that their acceptance in society is getting lower due to their mental illness. When asked about isolation and harm to their self-esteem, $47.22 \%$ of people $(n=204)$ reported that their isolation due to mental illness is harming their selfesteem (Table 2).

Table 1: Social Interaction of Mentally III Patients at the Workplace, $(n=432)$

\begin{tabular}{|lcc|}
\hline \multicolumn{1}{|c|}{ Statement } & Frequency & Percentage \\
\hline Has your work performance diminished after y our diagnose & & \\
of mental illness? & & \\
Yes & 125 & $28.94 \%$ \\
No & 89 & $20.60 \%$ \\
Dont know & 218 & $50.46 \%$ \\
Have you ever been discriminated against at the workplace & & \\
after being diagnosed with mental illness? & 116 & \\
Yes & 93 & $26.85 \%$ \\
No & 223 & $21.53 \%$ \\
Dont know & & \\
Have you ever thought of quitting your job because of your & & \\
illness? & 86 & $1.62 \%$ \\
Yes & 144 & $33.91 \%$ \\
No & 202 & $46.76 \%$ \\
Dont know & & \\
\hline
\end{tabular}

Table2: Social Interaction of Mentally |l| Patients in the Community, $(n=432)$

\begin{tabular}{|lcc|}
\hline \multicolumn{1}{|c|}{ Statement } & Frequency & Percentage \\
\hline Do you feel easy when someone asks about your illness? & & \\
Yes & 184 & $42.59 \%$ \\
No & 236 & $54.63 \%$ \\
Dont know & 12 & $2.78 \%$ \\
Do you think that your Socialization skills have worsened & & \\
youre your diagnosis of mental illness? & 256 & $61.81 \%$ \\
Yes & 148 & $34.26 \%$ \\
No & 17 & $3.94 \%$ \\
Dont know & & \\
Do you think that your acceptance in society is getting & 277 & \\
lower with your mental illness? & 124 & $28.70 \%$ \\
Yes & 31 & $7.18 \%$ \\
No & & \\
Dont know & & \\
lf your answer to the preceding question if yes, please & 204 & $47.22 \%$ \\
inform that, Does this isolation harm your self -esteem? & 148 & $34.26 \%$ \\
Yes & 80 & $18.52 \%$ \\
No & & \\
Dont know & & \\
\hline
\end{tabular}


When asked if they are stigmatized due to their mental illness, an overwhelming majority $(72.92 \%, n=315)$ reported in affirmation i.e. most people feel that they are stigmatized because of their illness. Interestingly, though felt stigmatizes but $43.06 \%(n=186)$ respondents reported that their stigma has not affected their ability to actively seek healthcare services. With regards to educational attainment, however, those reporting the negative effect of their stigma upon their educational attainment were more prominent $(30.79 \%, n=133)$ compared to those who reported no such effect $(14.12 \%, \mathrm{n}=61)$. When asked about mental illness-related stigma and its effect on their job, $35.42 \%(n=153)$ respondents reported that a negative effect on their experience stigma is present on their job. More than half $(52.08 \%)$ reported that their mental health-related stigma has adversely affected their relationships with other family members. Similarly, $65.05 \%(n=281)$ people reported that their overall socializing skills have been negatively affected by the mental illness-related stigma (Table 3).

\section{DISCUSSION}

The majority of study respondents (54.63\%, $n=236$ ) reported they feel uneasy when people ask them about their illness. The inhibitory potential of the stigma associated with mental disorder leads to further isolation and aggravation of mental illnesses. ${ }^{14}$ Other research studies support this notion, that mental disorders' associated stigma acts as a barrier to the successful integration of the disease personnel into society. It increases both the severity as well as the longevity of the disease. ${ }^{15}$

Various perceptions in society have impacts on their overall wellbeing and integration in the community. Studies show that the perception of people who see the mentally ill patients as a danger to society puts them at odds with the patients. It leads to gaps in their communication and hence the patients are isolated, leading to further deepening of the illness. ${ }^{16}$ According to studies professionals working in the health, sector perceives patients with mental illnesses are dangerous and they can harm other patients any

Table 3: Stigmatization of Mentally III Patients due to Mental IIIness, ( $n=432)$

\begin{tabular}{|lcc|}
\hline \multicolumn{1}{|c}{ Statement } & Frequency & Percentage \\
\hline Do you think, you are being stigmatized by people & & \\
because you have a mental illness? & & \\
Yes & 315 & $72.92 \%$ \\
No & 91 & $21.06 \%$ \\
Dont know & 26 & $6.02 \%$ \\
Has the stigma negatively affected your ability to actively & & \\
seek health services? & 128 & $29.63 \%$ \\
Yes & 186 & $43.06 \%$ \\
No & 118 & $28.31 \%$ \\
Dont know & & \\
Has this stigma negatively affected your educational & & \\
attainment? & 133 & $30.79 \%$ \\
Yes & 61 & $14.12 \%$ \\
No & 238 & $55.09 \%$ \\
Dont know & & \\
Has this stigma negatively affected your job-related & 153 & $35.42 \%$ \\
performance? & 79 & $18.29 \%$ \\
Yes & 200 & $46.30 \%$ \\
No & & \\
Dont know & & \\
Has this stigma negatively affected your relationship(s) & & \\
with your family members? & & $52.08 \%$ \\
Yes & 225 & $92.30 \%$ \\
No & 92 & $26.62 \%$ \\
Dont know & 115 & \\
Has this stigma negatively affected overall socializing & & \\
skills? & & \\
Yes & 281 & $25.49 \%$ \\
No & 110 & \\
Dont know & & \\
\hline
\end{tabular}


time. ${ }^{17}$ The stigmatization and isolation cost the community overall because such patients are being disabled to contribute to the community. ${ }^{18}$ It is only through systematic inquiries to find out barriers to remedial actions. A systematic review reported that stigma attached to mental disorders is the $4^{\text {th }}$ top-ranked barrier to seeking mental health services. Hence, every $4^{\text {th }}$ person with mental illness will forgo care because of the fear that he/she will be stigmatized because of the diagnosis and treatment. ${ }^{19}$

In the current study, attitude of people affects patients with mental health problems. This attitude ranges from the level of education and the evolutionary stage of the community as well as the gender of the coworkers and colleagues. A study conducted in Japan reveals that among the Japanese students, girls had a more positive and supportive attitude towards their colleagues suffering from any form of mental illness including schizophrenia, phobia, and depression. ${ }^{20}$ Similar findings were reported from Turkey, where it was noted that women tend to be more positive towards patients with mental illnesses and they tend to positively seek appropriate mental health services for themselves as compared to their male counterparts. ${ }^{21}$ It is essential to understand the perception and attitude of both the mentally ill patients, as well as their environment in a society. Proper care, utilization trends and successful completion of mental care all depend upon the perceptions of both the patient and those in their immediate surroundings. ${ }^{22}$

In Iraq, a large-scale survey concluded that people had a good understanding that the etiology of mental illness lies in genetics, brain damage, bad life events, and substance abuse. This knowledge, however, didn't establish a positive attitude towards people with mental disorders. They still perceived that those with mental disorders have brought the condition upon themselves and would prefer not to interact and socialize with people suffering from these conditions. Therefore, due to this negative stigmatic behavior, mentally ill people are secluded in the society, segregated at the workplace and experience delay in seeking proper mental health care. ${ }^{23}$ In the current study, those reporting worsening of socialization skills were $61.81 \% \quad(n=267)$. The majority participants $64.12 \%(n=277)$ reported that their acceptance in society is getting lower due to their mental illness. This stigmatizing approach whereby people in the community believe that the conditions are brought by nature to the person by the virtue of his deeds/ wrong deeds, complicate the living circumstances for the sufferers and their self-esteem is harmed. ${ }^{24}$

People with stronger self-discipline and a positive attitude were more likely to seek care earlier. Also, women were found more positive and open to seeking mental health care, including psychological support compared to men. ${ }^{25}$ Other studies showed, that help-seeking and maximum benefits from treatment/ therapies are conferred in children and adolescents compared to grown-up adults. Hence, focusing on the wellbeing of the children and adolescents needs to be prioritized both in primary prevention as well as secondary prevention of the mental health conditions. ${ }^{26}$ Other studies focusing on the nexus of gender and attitude towards proper mental health care suggested that those with more masculine traits i.e. lesser benevolence and more restrictive nature were less likely to accept psychological support than those with weaker masculine traits. Both this intra-gender and inter-gender attitude towards mental disorder and their treatment are well researched and well-established. ${ }^{27}$ In this study, for both genders in sampled population, $16.90 \%$ of people $(n=73)$ reported that their activities of daily living are not as efficient and effective as they were before their mental health condition. A percentage of $26.85 \%$ of study respondents reported that they have been discriminated against under their diagnosis of mental health illness. Such a negative attitude also dictates the resistance of the suffering person not to accept professional care in the long run. ${ }^{28}$ Around a quarter of our respondents $(19.91 \%$, $\mathrm{n}=86$ ) reported having considered quitting their job after being diagnosed with mental illness. Evidence shows that once the personal stigma roots-in, it is very difficult to go and the negative attitude towards seeking professional help is much stronger than that under the perceived personal stigma. ${ }^{29}$ Many other studies reviewed the role of gender and seeking psychological care. Most of the studies showed, that it is, in fact, the female gender is more open to discussion and seeking support than their counterparts. ${ }^{30,31}$

\section{CONCLUSION}

The findings reveal that people with mental illnesses do feel stigmatized and discriminated against in our society. These hurdles are faced at homes, healthcare centers, and a job environment. The issues are less severe at the family level but more at the workplace. $52 \%$ reported mental health adversely affected their 
relationships with family members. Moreover, $65.05 \%$ of people reported that their overall socializing skills have been negatively affected by the mental illness-related stigma. The majority $(72.9 \%)$ of the participants reported that they are stigmatized due to their mental health disorder. Also, the severity of the feelings depends upon the level of support one gets from his immediate family and friends. Spousal support is the most widespread support available to those with mental health illnesses, followed by dependence on parents and children.

\section{REFERENCES}

1. Vos T, Mathers CD. The burden of mental disorders: $A$ comparison of methods between the Australian burden of disease studies and the Global Burden of Disease study. Bull World Health Organ. 2018;78(4):427-38.

2. Spiers N, Qassem T, Bebbington P, McManus S, King M, Jenkins $R$, et al. Prevalence and treatment of common mental disorders in the English national population, 1993-2007. Br J Psychiatry. 2016;209(2):150-6.

3. United Nations. Sustainable development knowledge platform: SDG-13, Take urgent action to combat climate change and its impacts. 2016.

4. Elizabeth Reisinger Walker REM. Mortality in Mental Disorders and Global Disease Burden Implications. HHS Public Access. 2015;46(1):55-61.

5. Colton CW, Manderscheid RW. Congruencies in increased mortality rates, years of potential life lost, and causes of death among public mental health clients in eight states. Prev Chronic Dis. 2006;3(2):11-4.

6. Whiteford HA, Degenhardt L, Rehm J, Baxter AJ, Ferrari AJ, Erskine $\mathrm{HE}$, et al. Global burden of disease attributable to mental and substance use disorders: Findings from the Global Burden of Disease Study 2010. Lancet. 2013;382(9904):1575-86.

7. World Health Organization. Media centre: Mental disorders. Ment Disord Fact Sheet. 2016;16.

8. Falewicz A, Bak W. Private vs. public self-consciousness and self-discrepancies. Current Issues in Personality Psychology. 2016; 4(1), 58-64.

9. Wiens SE, Daniluk JC. Loss and change: The challenges of mothering an adult child with schizophrenia. Int $\mathrm{J}$ Healthc. 2017;3(1):2-6.

10. Andrade LH, Alonso J, Mneimneh Z, Wells JE, AlHamzawi A, Borges G, et al. Barriers to mental health treatment: Results from the WHO World Mental Health surveys. Psychol Med. 2014;44(6):1303-17.

11. Sartorius N, Gaebel W, Cleveland HR, Stuart H,Akiyama $\mathrm{T}$, Arboleda-Flórez J, et al. WPA guidance on how to combat stigmatization of psychiatry and psychiatrists. World Psychiatry. 2010;9(3):131-44.

12. Nishtar S, Faruqui AMA, Mattu MA, Mohamud KB, Ahmed A. The National Action Plan for the Prevention and Control of Non-communicable Diseases and Health Promotion in Pakistan--Cardiovascular diseases. J Pak Med Assoc. 2014;54(12 Suppl 3):S14-25.

13. Mirza I, Jenkins R. Risk factors, prevalence, and treatment of anxiety and depressive disorders in Pakistan: systematic review. BMJ. 2004;328(7443):7948.
14. Sareen J, Jagdeo A, Cox BJ, Clara I, Ten Have M, Belik $\mathrm{SL}$, et al. Perceived barriers to mental health service utilization in the United States, Ontario, and the Netherlands. Psychiatr Serv. 2007;58(3):357-64.

15. Henderson C, Robinson E, Corker E. Public knowledge, attitudes , social distance and reported contact regarding people with mental illness 2009 2015. 2016;134:23-33.

16. Aakansha S, Mattoo S, Grover S. Stigma associated with mental illness: Conceptual issues and focus on stigma perceived by the patients with schizophrenia and their caregivers. Indian J Soc Psychiatry. 2016;32(2):134-40.

17. Adewuya AO, Oguntade AA. Doctors' attitude towards people with mental illness in Western Nigeria. Soc Psychiatry Psychiatr Epidemiol. 2007 Nov;42(11):931-6.

18. Waheed W, Hughes-morley A, Woodham A, Allen G, Bower $P$. Overcoming barriers to recruiting ethnic minorities to mental health research?: a typology of recruitment strategies. 2015;111-17.

19. Clement S, Schauman O, Graham T, Maggioni F, EvansLacko S, Bezborodovs $\mathrm{N}$, et al. What is the impact of mental health-related stigma on help-seeking? A systematic review of quantitative and qualitative studies. Psychol Med. 2015;45(1):11-27.

20. Yoshioka K, Reavley NJ, MacKinnon AJ, Jorm AF. Stigmatising attitudes towards people with mental disorders: results from a survey of Japanese high school students. Psychiatry Res. 2014;215(1):229-36.

21. Savrun BM, Arikan K, Uysal O, Cetin G, Poyraz BC, Aksoy $C$, et al. Gender effect on attitudes towards the mentally ill: a survey of Turkish university students. Isr J Psychiatry Relat Sci. 2007;44(1):57-61.

22. Christopher JC, Maris JA. Counselling and Psychotherapy Research?: Linking research with practice Integrating mindfulness as self-care into counselling and psychotherapy training psychotherapy training. 2014;37-41.

23. Sadik S, Bradley M, Al-Hasoon S, Jenkins R. Public perception of mental health in Iraq. Int J Ment Health Syst. 2010;4(1):26-31.

24. Bos AER, Kanner D, Muris P, Janssen B, Mayer B. Mental illness stigma and disclosure: consequences of coming out of the closet. Issues Ment Health Nurs. 2009;30(8):509-13.

25. Magaard JL, Seeralan T, Schulz H, Bru AL. Factors associated with help-seeking behaviour among individuals with major depression?: A systematic review. 2017;117-23

26. Dardas LA, Silva SG, Water B Van De, Vance A, Smoski MJ, Noonan D, et al. Psychosocial Correlates of Jordanian Adolescents' Help-Seeking Intentions for Depression?: Findings From a Nationally Representative School Survey. 2017;111-19.

27. Seidler ZE, Dawes AJ, Rice SM, Oliffe JL, Dhillon HM. The role of masculinity in men ' $s$ help-seeking for depression?: A systematic review. Clin Psychol Rev [Internet]. 2016;49:106-18. Available from: http://dx.doi.org/10.1016/j.cpr.2016.09.002

28. Schomerus G, Matschinger $H$, Angermeyer MC. The stigma of psychiatric treatment and help-seeking intentions for depression. Eur Arch Psychiatry Clin Neurosci. 2009;259(5):298-306.

29. Eisenberg D, Downs MF, Golberstein E, Zivin K. Stigma and help seeking for mental health among college students. Med Care Res Rev. 2009;66(5):522-41. 
30. Mackenzie C, Erickson J, Deane F, Wright M. Changes in attitudes toward seeking mental health services: A 40year cross-temporal meta-analysis Publication Details. Clin Psychol Rev. 2014;34(2):99-106.

31. Holzinger A, Floris F, Schomerus G, Carta MG, Angermeyer MC. Gender differences in public beliefs and attitudes about mental disorder in western countries: A systematic review of population studies. Epidemiol Psychiatr Sci. 2012;21(1):73-85.
DATA SHARING STATEMENT: The data that support the findings of this study are available on request from the corresponding author. The data are not publicly available due to privacy or ethical restrictions.

CONFLICT OF INTEREST: Authors declared no conflict of interest.

GRANTED SUPPORT AND FINANCIAL DISCLOSURE: Nil

\section{AUTHOR'S CONTRIBUTION}

Following authors have made substantial contributions to the manuscript as under

Daniel F: $\quad$ Concept and design of study, Collection

of data, statistical analysis

Suliman M: Writing of manuscript, critical review of manuscript

Ghani N: Analysis and interpretation of data, Data collection, bibliography

Authors agree to be accountable for all aspects of the work in ensuring that questions related to the accuracy or integrity of any part of the work are appropriately investigated and resolved. 